Original Research Article

\title{
A prospective study of $\mathbf{N}$-acetylcysteine treatment in drug-induced fulminant hepatic failure
}

\author{
Tauseef Nabi ${ }^{1}$, Nadeema Rafiq ${ }^{2 *}$, Quratul Ain Arifa ${ }^{3}$
}

\begin{abstract}
${ }^{1}$ Department of Endocrinology, Government Medical College, Srinagar, Jammu and Kashmir, India

${ }^{2}$ Department of Physiology,

${ }^{3}$ Department of Community Medicine, Government Medical College, Baramulla, Jammu and Kashmir, India
\end{abstract}

Received: 22 February 2019

Revised: 19 March 2019

Accepted: 28 March 2019

\section{*Correspondence to: \\ Dr. Nadeema Rafiq, \\ Email: dr.nadeema@gmail.com}

Copyright: (C) the author(s), publisher and licensee Medip Academy. This is an openaccess article distributed under the terms of the Creative Commons Attribution NonCommercial License, which permits unrestricted noncommercial use, distribution, and reproduction in any medium, provided the original work is properly cited.

\begin{abstract}
Background: Acute liver failure (ALF) is a rare but severe, life-threatening, complex, multisystemic gastroenterological emergency. Its rapid progression and high mortality demand early diagnosis and expert management. Drug-induced ALF (DI-ALF) remains the uncommon cause of ALF in India. To date, there is no established treatment for DI-ALF other than liver transplantation and little is known about the use of $\mathrm{N}$-acetylcysteine (NAC) in DI-ALF. A prospective casecontrol study was carried with the aim to determine the effect of NAC on mortality of DI-FHF patients and also to evaluate the safety and efficacy of NAC use.

Methods: A total of 18 patients with a diagnosis of DI-FHF were included in the study. 10 patients received NAC infusion for 72 hours whereas the control group received placebo. The variables evaluated were demographic, signs and symptoms, biochemical parameters, outcome and length of hospital stay.

Results: Out of 18 DI-FHF patients, $13(72.2 \%)$ had anti-tuberculosis therapy (ATT) induced FHF and $5(27.8 \%)$ patients had ayurvedic induced FHF. The two groups were comparable for the various baseline characteristics (age, INR, alanine aminotransferase, creatinine, albumin, grade of encephalopathy, etc.). The mortality decreased to $20 \%$ with the use of NAC versus $75 \%$ in the control group $(\mathrm{P}=0.023)$. Use of NAC was associated with a shorter length of hospital stay of survived patients $(\mathrm{P}=0.043)$. Moreover, the overall survival was improved by NAC $(\mathrm{P}=0.023)$ in DI-FHF. ATT induced FHF showed better outcome as compared to ayurvedic induced FHF use $(\mathrm{P}=0.019)$.

Conclusions: Author recommended the use of NAC along with conventional treatments in patients with DI-FHF in non-transplant centers while awaiting referrals. ATT induced FHF showed better outcome as compared to ayurvedic induced FHF with NAC administration and its use was safe.
\end{abstract}

Keywords: Acute liver failure, Anti-tuberculosis therapy, Drug-induced ALF, Drug-induced fulminant hepatic failure, $\mathrm{N}$-acetylcysteine

\section{INTRODUCTION}

Acute liver failure (ALF) is a relatively rare liver disorder that often leads to devastating consequences. It is one of the most life threatening hepatological emergency encountered in clinical practice. ALF is a syndrome characterized by the development of hepatic encephalopathy (HE) together with signs of hepatocellular insufficiency, especially jaundice and coagulation disorders, in patient who previously had normal liver. ${ }^{1}$ Fortunately, it is a rare disease with 2000 to 3000 reported cases in the United States per year and is responsible for $6 \%$ of liver transplants. ${ }^{2,3}$

Etiology of ALF is diverse and shows wide geographical variation. The most important step in the management of ALF is to identify the cause which helps in the execution of targeted therapies and antidotes, when available. The main etiological factor includes viral, drugs, autoimmune, toxin and indeterminate. ${ }^{4}$ Viral hepatitis is the commonest cause of ALF in the Indian subcontinent and it accounts for $90 \%$ of cases. ${ }^{5}$ 
Drug-induced ALF (DI-ALF) remains the most common cause of ALF in the UK and USA. ${ }^{6,7}$ Specifically, in the UK, paracetamol overdose causes approximately $57 \%$ of all ALF with non-paracetamol drugs accounting for a further $11 \%{ }^{6}$ DI-ALF is largely a diagnosis of exclusion because there are no laboratory, imaging, or biopsy findings that are specific for hepatotoxicity from a particular drug. ${ }^{8}$

The drugs responsible vary by location and prevailing drug use. The drugs most commonly implicated in ALF include anti-tuberculosis therapies (ATT), herbal and dietary supplements, sulpha-containing drugs, nitrofurantoin, phenytoin, sodium valproate, flutamide and amoxicillinclavulanate. ${ }^{9,10}$ Herbal or adulterated traditional or complementary medications are also a notable cause in east Asia. ${ }^{11}$ Liver damage induced by drugs other than paracetamol has been the most frequent cause of safetyrelated marketing withdrawals in the past 50 years. ${ }^{12}$ Fewer than $10 \%$ of drug-induced liver injury (DILI) progress to ALF. ${ }^{10}$ However, up to $80 \%$ of patients who develop liver failure might die or require transplantation. ${ }^{10,11}$

Mortality related to ALF can be attributed to three complications in particular cerebral edema, multiorgan dysfunction syndrome (MODS), and sepsis. The overall management strategy starts with the identification of cause and an initial assessment of prognosis. Because there is no specific therapy for ALF, treatment is limited to supportive measures, allowing the liver time to regenerate. Treatment of suspected DI-FHF is to stop using the drug before the development of irreversible hepatic failure.

Although many people recover with supportive treatment, Orthotropic Liver Transplantation (OLT) remains the only definitive therapy for patients who are unable to achieve sufficient hepatocyte regeneration on supportive treatment. OLT has made a significant impact on survival of patients with ALF but the facility is largely unaffordable and only available in limited medical centers. ${ }^{7,13}$ Therefore, better cost-effective alternatives are needed in locations where facility is not available. There is limited availability of specific antidotes to DI-ALF. Two randomized controlled trials showed no benefit of corticosteroids in ALF and even demonstrated a poorer outcome in those with DI-ALF. ${ }^{14,15} \mathrm{~N}$-acetylcysteine (NAC) has a well-established role in paracetamol-induced ALF although it is now also recommended in selected cases of non-paracetamol ALF because of its multiple mechanisms of action. ${ }^{16-18}$ Some antidotes which have found to be effective in DILI are carnitine for valproic acid toxicity. ${ }^{19}$ Cholestyramine may mitigate leflunomide toxicity. ${ }^{20}$ Ursodeoxycholic acid, silymarin, and glycyrrhizin have been reported to be effective, but evidence remained largely anecdotal. ${ }^{21}$

NAC is a thiol-containing agent that scavenges free oxygen radicals and replenishes cellular mitochondrial and cytosolic glutathione. ${ }^{22}$ Its anti-inflammatory, antioxidant, inotropic, and vasodilating effect has been proved from various trials. ${ }^{23}$ NAC may benefit patients either by improving systemic hemodynamics and tissue oxygen delivery or via other mechanisms. ${ }^{24,25}$ Role of NAC in DIFHF has not been studied in controlled trials except for case reports and the results have been reassuring. ${ }^{26}$ The present study was carried out to understand the role of NAC in DI-FHF, in a centre in Kashmir (North India) without liver transplant facility with the aim to determine the effect of NAC on mortality of DI-FHF patients and also to evaluate the safety and efficacy of NAC and its impact on the duration of hospital stay.

\section{METHODS}

It was a single centre prospective study of adult patients with DI-FHF. This study was carried out in the Department of Gastroenterology of Sher-i-Kashmir Institute of Medical Science (SKIMS), Soura, Jammu and Kashmir, India. The study was approved by the institutional ethical committee (SKIMS). Informed consent was obtained from all the recruited subjects.

Total of 18 patients with diagnoses of DI-FHF who fulfilled eligibility criteria were recruited in the study. This study was conducted over a period of three years from 2011 to 2014. Information regarding various demographics characteristics was taken through wellstructured questionnaires from all subjects. Besides a detailed history, physical examination and biochemical workup which included baseline investigations, liver function test (LFT), coagulogram of subjects were carried out.

\section{Eligibility criteria}

Inclusion criteria included patients having age $>18$ years and DI-FHF which was defined as biochemical evidence of acute liver injury with INR $\geq 1.5$ and any degree of encephalopathy caused by the illness of duration $<8$ weeks in a patient with no prior known liver disease with history of hepatotoxic drug exposure/intake, including homeopathic, herbal medications at least for $>2$ weeks. ${ }^{1}$ Exclusion criteria includes viral ALF, autoimmune ALF, acute on chronic liver failure, ALF during pregnancy and hepatic shock.

\section{Procedure}

After FHF was diagnosed, a detailed history was taken for any hepatotoxic drug intake, including homeopathic, herbal medications and intravenous drug abuse. DI-FHF is largely a diagnosis of exclusion because there are no laboratory, imaging, or biopsy findings that are specific for hepatotoxicity from a particular drug. Roussel Uclaf Causality Assessment Method (RUCAM) was used to calculate the causality score for individual cases. ${ }^{27}$ Blood samples of all the patients were taken for exclusion of other etiological diagnoses, which included hepatitis B surface antigen (HBsAg), hepatitis B core IgM (HBc- 
$\operatorname{IgM}$ ), hepatitis A virus IgM (HAV-IgM), and hepatitis E virus IgM (HEV-IgM), hepatitis D virus (IgG and IgM anti-HDV), anti HCV (hepatitis C virus), ANA (antinuclear antibody), ASMA (anti smooth muscle antibody), Wilson profile (serum ceruloplasmin, serum copper) and iron profile. HSV (herpes simplex virus), CMV (cytomegalovirus) and EBV (Epstein barr virus) serology were done if non hepatotropic viruses were suspected as a cause of FHF in immunocompromised patients. Imaging was obtained to rule out biliary processes, hepatic vascular abnormalities, and intrahepatic lesions. Liver injury pattern was determined by below formula into hepatocellular, cholestatic and mixed. Subjects were then randomized by simple random method into two groups.

Calculation of $\mathrm{R}$ value ${ }^{27}$

ALT/AST value divided by its ULN = fold elevation/fold elevation above ULN for alkaline phosphatase.

\section{Definitions}

- $\quad$ Hepatocellular injury $=\mathrm{R}>5$,

- $\quad$ Cholestatic injury $=\mathrm{R}<2$,

- $\quad$ Mixed injury $=\mathrm{R}>2<5$.

\section{NAC group}

About 10 DI-FHF patients who fulfilled the eligibility criteria were treated with intravenous NAC for duration of 72 hours.

\section{Control group}

About 8 DI-FHF patients who received 5\% dextrose (placebo) infusion for 72 hours.

\section{Study medication}

After informed written consent was obtained from next of kin, the patients in NAC group were administered intravenous NAC with initial loading dose of $150 \mathrm{mg} / \mathrm{kg}$ over 1 hour, followed by $12.5 \mathrm{mg} / \mathrm{kg} / \mathrm{hr}$ for 4 hours and then continuous infusion of $6.25 \mathrm{mg} / \mathrm{kg} / \mathrm{hr}$ for remaining 67 hours. Patients in Control group were given 5\% dextrose infusion (placebo) for 72 hours. All the ethical considerations were taken care of during the study. Patients were given the option of liver transplant (to be done at the hospital with transplantation facility) at various stages of study when indicated. No patient underwent OLT in this study.

\section{Supportive treatment}

All patients were managed with the standard supportive care treatment with stoppage of the offending drug. ${ }^{28}$ The patients received treatment of and prevention for the complications of FHF. ${ }^{29}$ The treatment mainly involved continuous intravenous dextrose to prevent hypoglycemia, proton pump inhibitors for stress-related ulcers and lactulose enema. With the development of advanced hepatic encephalopathy, intensive care management, fluid and electrolyte balance, midazolam sedation and mannitol infusion in case of raised intracranial pressure. Fresh frozen plasma and vitamin $\mathrm{K}$ was given in only those patients who had a spontaneous bleed. Blood and urine cultures were obtained in suspected cases of sepsis, which were then treated as per sensitivity. Renal impairment was defined as serum creatinine level of more than $1.5 \mathrm{mg} / \mathrm{dl}$.

\section{Monitoring}

Response to treatment was monitored clinically (Grade of encephalopathy) and biochemically (bilirubin, PT, INR etc.). In addition, morbidity and mortality was also assessed. Patients were followed till discharge or death in hospital.

\section{Statistical analyses}

In univariate analysis, the categorical variables were compared in the two groups by using $\chi^{2}$ test or Fisher exact test where appropriate. For continuous variables, the independent sample $t$ test was used. $\mathrm{P}$ values $<0.05$ was considered statistically significant. All the analyses were performed by the Statistical Package for Social Sciences (SPSS, Chicago, IL, USA, version 21.0).

\section{RESULTS}

In this study, out of 18 DI-FHF patients, 13 (72.2\%) had ATT induced FHF and $5(27.8 \%)$ patients had ayurvedic induced FHF. There were 10 patients in the NAC group and 8 patients in control group. Table 1 shows the distribution of baseline characteristics (both categorical and continuous) of two groups of DI-FHF. All the patients were of Kashmiri ethnicity. The mean age in NAC group was $40.50 \pm 15.40$ years and in control group was $38.98 \pm 20.20$ years $(\mathrm{P}=0.857)$. Majority of the patients were females $(72.2 \%)$ and they were equally distributed between two groups. Coma grade at the time of admission showed that majority of patients $(66.67 \%)$ had grade I and II encephalopathy. The patients in both the groups were comparable for the different grade of encephalopathy $(\mathrm{P}=0.514)$. Depending on the pattern of liver injury, hepatocellular pattern was most common followed by mixed and cholestatic pattern and they were comparable between groups. The two treatment groups did not differ significantly with respect to fever, vomiting, rash, MELD Score, interval between jaundice and encephalopathy and biochemical measures of liver injury (INR, bilirubin, AST, ALT, and albumin).

The mean number of days of admission in hospital of survived patients in NAC group was $8.68 \pm 3.10$ versus $12.3 \pm 3.90$ in controls. The difference was statistically significant $(\mathrm{P}=0.043)$ (Table 2).

A total of 8 of $18(44.4 \%)$ patients died with FHF complications; 2 (20\%) patients belonged to NAC group 
and $6(75 \%)$ patients to control group (Chi Square=5.143, $\mathrm{P}=0.023)$. More patients $(80 \%)$ survived in NAC group than in the Control group (25\%) and the difference was statistically significant (Table 3 ). When survival was considered between different etiologies of DI-FHF, ATT induced FHF showed significant improved in survival than ayurvedic induced FHF with NAC administration $(\mathrm{P}=0.019)$ (Table 4).
Logistic regression analysis was performed in order to study the role of independent risk factors on mortality in DI-FHF patients. In the study not using NAC, age $>55$ years, III-IV grade of encephalopathy, renal impairment and MELD score >30 were the independent prognostic factors determining mortality.

Table 1: Baseline characteristics of study subjects in the two groups of DI-FHF.

\begin{tabular}{|c|c|c|c|}
\hline Characteristics & NAC group $(\mathrm{N}=10)$ & Control group $(\mathrm{N}=8)$ & P-value* \\
\hline \multicolumn{4}{|l|}{ Categorical variables (n (\%)) } \\
\hline Female gender & $7(70 \%)$ & $6(75 \%)$ & 0.819 \\
\hline \multicolumn{3}{|l|}{ Hepatic- encephalopathy } & \multirow{5}{*}{0.514} \\
\hline Grade I & $4(40 \%)$ & $3(37.5 \%)$ & \\
\hline Grade II & $2(20 \%)$ & $3(37.5 \%)$ & \\
\hline Grade III & $3(30 \%)$ & $2(25 \%)$ & \\
\hline Grade IV & $1(10 \%)$ & $0(0 \%)$ & \\
\hline Fever & $4(40 \%)$ & $2(25 \%)$ & 0.514 \\
\hline Vomiting & $3(30 \%)$ & $2(25 \%)$ & 0.819 \\
\hline Rash & $2(20 \%)$ & $1(12.5 \%)$ & 0.680 \\
\hline Hepatocellular pattern of liver injury & $6(60 \%)$ & $4(50 \%)$ & 0.680 \\
\hline Cholestatic pattern & $1(10 \%)$ & $2(25 \%)$ & 0.409 \\
\hline Mixed pattern & $3(30 \%)$ & $2(25 \%)$ & 0.819 \\
\hline \multicolumn{4}{|l|}{ Continuous variables (mean \pm SD) } \\
\hline Age (years) & $40.50 \pm 15.40$ & $38.98 \pm 20.20$ & 0.857 \\
\hline INR & $2.67 \pm 1.19$ & $2.57 \pm 0.98$ & 0.851 \\
\hline Bilirubin (mg/dl) & $21.12 \pm 8.94$ & $20.87 \pm 9.54$ & 0.958 \\
\hline $\operatorname{AST}(\mathrm{mg} / \mathrm{dl})$ & $1526 \pm 502$ & $1396 \pm 512$ & 0.595 \\
\hline $\operatorname{ALT}(\mathrm{mg} / \mathrm{dl})$ & $994.6 \pm 617.4$ & $945.8 \pm 589.7$ & 0.867 \\
\hline Albumin $(\mathrm{g} / \mathrm{dl})$ & $3.24 \pm 0.55$ & $3.60 \pm 0.44$ & 0.152 \\
\hline Creatinine $(\mathrm{mg} / \mathrm{dl})$ & $1.42 \pm 0.72$ & $1.37 \pm 0.67$ & 0.881 \\
\hline Interval between jaundice and encephalopathy (days) & $43 \pm 14.4$ & $49 \pm 16.2$ & 0.418 \\
\hline MELD Score & $29.82 \pm 6.24$ & $27.48 \pm 5.64$ & 0.421 \\
\hline
\end{tabular}

*P-value $<0.05$ is considered statistically significant, $\mathrm{n}=$ Number, $\mathrm{SD}=$ Standard deviation.

Table 2: Length of hospital stay in NAC group and controls.

\begin{tabular}{|llll|}
\hline Etiology & NAC group & Control & P value* \\
\hline ATT & $87.5 \%$ & $20 \%$ & \multirow{2}{*}{0.019} \\
$\mathrm{~N}=13$ & $\mathrm{~N}=8$ & $\mathrm{~N}=5$ & \\
\hline Ayurvedic & $50 \%$ & $33.3 \%$ & \multirow{2}{*}{0.738} \\
$\mathrm{~N}=5$ & $\mathrm{~N}=2$ & $\mathrm{~N}=3$ & \\
\hline
\end{tabular}

$* \mathrm{P}$-value $<0.05$ is considered statistically significant.

Table 3: Survival of study subjects in DI-FHF.

\begin{tabular}{|c|c|c|c|}
\hline & \multicolumn{2}{|c|}{ Mean \pm SD (range) } & \multirow{2}{*}{$\begin{array}{l}\mathbf{P} \\
\text { value* }\end{array}$} \\
\hline & NAC group & Control group & \\
\hline $\begin{array}{l}\text { Duration of } \\
\text { hospital stay } \\
\text { of survived } \\
\text { patients } \\
\text { (days) }\end{array}$ & $\begin{array}{l}8.68 \pm 3.10 \\
(6-14)\end{array}$ & $\begin{array}{l}12.3 \pm 3.90 \\
(10-18)\end{array}$ & 0.043 \\
\hline
\end{tabular}

Table 4: Survival for study subjects stratified by etiology of DI-FHF.

\begin{tabular}{|llll|} 
& $\begin{array}{l}\text { NAC group } \\
\text { n }(\%)\end{array}$ & $\begin{array}{l}\text { Control group } \\
\text { n }(\%)\end{array}$ & $\begin{array}{l}\text { P } \\
\text { value* }\end{array}$ \\
\hline Survival & $8(80 \%)$ & $2(25 \%)$ & 0.023 \\
\hline
\end{tabular}

$* \mathrm{P}$-value $<0.05$ is considered statistically significant.

In this study, no adverse effects were noted in patients which could have been attributed to NAC administration in DI-FHF patients.

\section{DISCUSSION}

ALF is a rare but severe multisystemic disease and its rapid progression and high mortality necessitates early diagnosis and expert management. DI-ALF remains the most common cause of ALF in the UK and USA. ${ }^{6,7}$ DI-ALF is largely a diagnosis of exclusion. OLT has remained the 
treatment of choice for DI-FHF. ${ }^{29,30}$ Data suggested some benefits of NAC use in non-paracetamol induced ALF, while data on use of NAC in non-paracetamol drug induced ALF is scarce. ${ }^{17,18,31}$ Only case reports of NAC use for ATT and other drug induced ALF exist. ${ }^{26,32}$

So, study on the use, safety and efficacy of NAC in DIFHF was warranted. Therefore, author carried out a prospective study to access the role of NAC in DI-FHF in particular at a medical centre (SKIMS, Soura) lacking liver transplantation facility.

In this study, out of 18 DI-FHF patients, 13 (72.2\%) had ATT induced FHF and $5(27.8 \%)$ patients had ayurvedic induced FHF. ATT also topped the list of DI-ALF in India as studied by Devarbhavi $\mathrm{H}$, where acetaminophen use is rare and tuberculosis is prevalent. ${ }^{33}$ In India, antituberculosis drugs account for nearly three-quarters of all DI-ALF cases. ${ }^{34}$

In this study, the majority of the patients were females $(72.2 \%)$ and middle-aged (39.60 \pm 14.30 years). In a case series of 128 patients with ALF (including 21 children <18 years old) from Bangalore, India, the mean age was 38 years. $^{35,36}$ While in ALFSG study, the average age of subjects was 44 years and the majority were women $(71 \%){ }^{9}$

A total of 8 of $18(44.4 \%)$ patients died with DI-FHF complications, $2(20 \%)$ patients belonged to NAC group and $6(75 \%)$ patients to control group (Chi Square $=5.143$, $\mathrm{P}=0.023$ ). While other studies, from India showed mortality ranged between $67.1 \%$ to $70 \%$ which is higher than ours. ${ }^{37,38}$ The reason for higher mortality in their study is because their patients had more severe disease as suggested by higher MELD, INR, and higher grade of HE.

Author found significant improvement in the survival of patients treated with NAC, mortality decreased to $20 \%$ with the use of NAC versus $75 \%$ in control group. On stratification of patients between different etiologies of DIFHF i.e., ATT induced FHF showed significant improved in survival than ayurvedic induced FHF with NAC administration $(\mathrm{P}=0.019)$. Cheng $\mathrm{SL}$ et al, showed the protective effect of NAC on ATT-induced hepatotoxicity. ${ }^{39}$

Furthermore, use of NAC was safe and was associated with a shorter length of hospital stay of survived patients $(\mathrm{P}=0.043)$. No adverse effects were noted in patients that could have been attributed to NAC administration. Darweesh SK et al, in his study reported NAC decreased encephalopathy, hospital stay, ICU admission, and failure of other organs. ${ }^{40}$

To the best of the knowledge, no prospective study has reported benefits of NAC use in DI-FHF patients. The major strengths of this study included prospective cases and controls. Some of the limitations of this study included small sample size, single centre study and the duration of follow up was short (hospital stay till discharge or death in the hospital).

\section{CONCLUSION}

ATT was the class of drugs most frequently associated with DI-FHF. Author suggested that the use of NAC along with conventional treatments will benefit the patients with DI-FHF.

\section{ACKNOWLEDGEMENTS}

Authors would like to thank Department of Gastroenterology of Sher-i-Kashmir Institute of Medical Science, Jammu and Kashmir, India for their support during study.

\section{Funding: No funding sources \\ Conflict of interest: None declared}

Ethical approval: The study was approved by the Institutional Ethics Committee of Sher-i-Kashmir Institute of Medical Science, Soura, J\&K, India

\section{REFERENCES}

1. Wendon J, Cordoba J, Dhawan A, Larsen FS, Manns M, Nevens F, et al. EASL Clinical Practical Guidelines on the management of acute (fulminant) liver failure. J Hepatol. 2017;66(5):1047-81.

2. Hoofnagle JH, Carithers RL, Shapiro C, Ascher N. Fulminant hepatic failure: summary of a workshop. Hepatol. 1995;21(1):240-52.

3. Health Resources and Services Administration, Healthcare Systems Bureau, Division of Transplantation. Rockville, Maryland; 2007.

4. Ostapowicz G, Fontana RJ, Schiødt FV, Larson A, Davern TJ, Han SH, et al. Results of a prospective study of acute liver failure at 17 tertiary care centers in the United States. Ann Internal Med. 2002;137(12):947-54.

5. Acharya SK, Dasarathy S, Kumer TL, Sushma S, Prasanna KS, Tandon A, et al. Fulminant hepatitis in a tropical population: clinical course, cause, and early predictors of outcome. Hepatol. 1996;23(6):1448-55.

6. Bernal W, Wendon J. Acute liver failure. New Eng J Med. 2013;369(26):2525-34.

7. Lee WM. Acute liver failure in the United States. Seminars Liver Dis. 2003;23(3):217-26.

8. Chalasani N, Bonkovsky HL, Fontana R, Lee W, Stolz A, Talwalkar J, et al. Features and outcomes of 899 patients with drug-induced liver injury: the DILIN prospective study. Gastroenterol. 2015;148(7):134052.

9. Reuben A, Koch DG, Lee WM. Drug-induced acute liver failure: results of a US multicenter, prospective study. Hepatol. 2010;52(6):2065-76.

10. Andrade RJ, Lucena MI, Fernández MC, Pelaez G, Pachkoria K, García-Ruiz E, et al. Drug-induced liver injury: an analysis of 461 incidences submitted to the 
Spanish registry over a 10-year period. Gastroenterol. 2005;129(2):512-21.

11. Wai CT, Tan BH, Chan CL, Sutedja DS, Lee YM, Khor C, et al. Drug-induced liver injury at an Asian center: a prospective study. Liver Int. 2007;27(4):46574.

12. Navarro VJ, Senior JR. Drug-related hepatotoxicity. N Engl J Med. 2006;354:731-9.

13. Schiødt FV, Atillasoy E, Shakil AO, Schiff ER, Caldwell C, Kowdley KV, et al. Etiology and outcome for 295 patients with acute liver failure in the United States. Liver Transplantation Surg. 1999;5(1):29-34.

14. European Association for the Study of the Liver. Randomized trial of steroid therapy in acute liver failure. Gut. 1979;20:620-3.

15. Karkhanis J, Verna EC, Chang MS, Stravitz RT, Schilsky M, Lee WM, et al. Acute Liver Failure Study Group. Steroid use in acute liver failure. Hepatol. 2014;59(2):612-21.

16. Polson J, Lee WM. AASLD position paper: the management of acute liver failure. Hepatol. 2005;41(5):1179-97.

17. Lee WM, Hynan LS, Rossaro L, Fontana RJ, Stravitz RT, Larson AM, et al. Intravenous N-acetylcysteine improves transplant-free survival in early stage nonacetaminophen acute liver failure. Gastroenterol. 2009;137(3):856-64.

18. Nabi T, Nabi S, Rafiq N, Shah A. Role of Nacetylcysteine treatment in non-acetaminopheninduced acute liver failure: a prospective study. Saudi J Gastroenterol Off J Saudi Gastroenterol Assoc. 2017;23(3):169.

19. Nakamura M, Nagamine T. The effect of carnitine supplementation on hyperammonemia and carnitine deficiency treated with valproic acid in a psychiatric setting. Innovations Clin Neurosci. 2015;12(9-10):18.

20. Sevilla-Mantilla C, Ortega L, Agúndez JA, FernandezGutierrez B, Ladero JM, Díaz-Rubio M. Leflunomideinduced acute hepatitis. Dig Liver Dis. 2004;36(1):824.

21. Giordano C, Rivas J, Zervos X. An update on treatment of drug-induced liver injury. J Clin Translational Hepatol. 2014;2(2):74.

22. Cotgreave IA. N-Acetylcystei ne: Pharmacological Considerations and Experimental and Clinical Applications. Adv Pharmacol. 1996;38:205-227.

23. Harrison P, Wendon J, Williams R. Evidence of increased guanylate cyclase activation by acetylcysteine in fulminant hepatic failure. Hepatol. 1996;23(5):1067-72.

24. Rank N, Michel C, Haertel C, Lenhart A, Welte M, Meier-Hellmann A, et al. N-acetylcysteine increases liver blood flow and improves liver function in septic shock patients: results of a prospective, randomized, double-blind study. Crit Care Med. 2000;28(12):3799807.

25. Bémeur C, Vaquero J, Desjardins P, Butterworth RF. $\mathrm{N}$-acetylcysteine attenuates cerebral complications of non-acetaminophen-induced acute liver failure in mice: antioxidant and anti-inflammatory mechanisms. Metab Brain Dis. 2010;25(2):241-9.

26. Rodriguez TS, Miles M, McLeod M. A23 a case of acute liver dysfunction due to trimethoprimsulfamethoxazole treated with n-acetylcysteine. J Can Assoc Gastroenterol. 2018;1(2):39.

27. Danan G, Benichou C. Causality assessment of adverse reactions to drugs-I. A novel method based on the conclusions of international consensus meetings: application to drug-induced liver injuries. J Clin Epidemiol. 1993;46(11):1323-30.

28. Lee WM, Larson AM, Stravitz RT. AASLD position paper: the management of acute liver failure: update 2011. Hepatol. 2011;55(55):965-7.

29. Russo MW, Galanko JA, Shrestha R, Fried MW, Watkins P. Liver transplantation for acute liver failure from drug induced liver injury in the United States. Liver Transplantation. 2004;10(8):1018-23.

30. Mindikoglu AL, Magder LS, Regev A. Outcome of liver transplantation for drug-induced acute liver failure in the United States: analysis of the United Network for Organ Sharing database. Liver Transplantation. 2009;15(7):719-29.

31. Chughlay MF, Kramer N, Spearman CW, Werfalli M, Cohen K. N-acetylcysteine for non-paracetamol druginduced liver injury: a systematic review. Brit J Clin Pharmacol. 2016;81(6):1021-9.

32. Mudalel ML, Dave KP, Hummel JP, Solga SF. Nacetylcysteine treats intravenous amiodarone induced liver injury. WJG. 2015;21(9):2816.

33. Devarbhavi H, Dierkhising R, Kremers WK, Sandeep MS, Karanth D, Adarsh CK. Single-center experience with drug-induced liver injury from India: causes, outcome, prognosis, and predictors of mortality. Am J Gastroenterol. 2010;105:2396-404.

34. Devarbhavi H. Acute liver failure induced by antiinfectious drugs: causes and management. Current Hepatol Rep. 2017;16(4):276-85

35. Devarbhavi H, Patil M, Reddy VV, Singh R, Joseph T, Ganga D. Drug-induced acute liver failure in children and adults: Results of a single-centre study of 128 patients. Liver Int. 2018;38(7):1322-9.

36. Rathi C, Pipaliya N, Patel R, Ingle M, Phadke A, Sawant P. Drug induced liver injury at a tertiary hospital in india: etiology, clinical features and predictors of mortality. Ann Hepatol. 2017;16(3):44250.

37. Kumar R, Bhatia V, Khanal S, Sreenivas V, Gupta SD, Panda SK, et al. Antituberculosis therapy-induced acute liver failure: magnitude, profile, prognosis, and predictors of outcome. Hepatol. 2010;51(5):1665-74.

38. Devarbhavi H, Dierkhising R, Kremers WK. Antituberculosis therapy drug-induced liver injury and acute liver failure. Hepatol. 2010;52(2):798-9.

39. Cheng SL. Protective effect of $\mathrm{N}$-acetylcysteine on antituberculosis drug-induced hepatotoxicity. Eur Respir J. 2016;48(60):2716.

40. Darweesh SK, Ibrahim MF, El-Tahawy MA. Effect of $\mathrm{N}$-Acetylcysteine on mortality and liver transplantation rate in non-acetaminophen-induced 
acute liver failure: a multicenter study. Clin Drug Investigation. 2017;37(5):473-82.
Cite this article as: Nabi T, Rafiq N, Arifa QA. A prospective study of $\mathrm{N}$-acetylcysteine treatment in drug-induced fulminant hepatic failure. Int J Basic Clin Pharmacol 2019;8:1000-6. 